DOI: https://doi.org/10.24144/2409-6857.2019.1(53).19-26

УДК 332.62(477.7): 339.9

Катуніна O.C.

\title{
ЗАСТОСУВАННЯ ДИНАМІЧНИХ ФАКТОРНИХ МОДЕЛЕЙ ДО АНАЛІЗУ МАКРОЕКОНОМІКИ ДЕЯКИХ ЄВРОПЕЙСЬКИХ ТА ПОСТРАДЯНСЬКИХ КРАЇН
}

\begin{abstract}
В роботі розглянуто побудову моделей динаміки змінення макроекономічних показників ВВП за ПКС для окремих країн Свропи. Для моделювання розвитку економічної системи з метою визначення прогнозних значень окремих часових рядів застосовано динамічний факторний аналіз. Використаний метод поєднує методологію класичного факторного аналізу з класичними авторегресійними схемами, які враховують динамічні зміни в системах. Особливістю розробленого алгоритму є можливість мінімізації похибки для кожного часового ряду з системі показників в ех роst прогнозі, а також застосування усереднених прогнозних значень на кожному крочі рекурсивного прогнозу. Наводяться інтервальні $i$ рекурсивні прогнози зміни ВВП за ППС до 2020 року включно, отримані при аналізі статистичних даних за 1998 2017 роки.
\end{abstract}

Ключові слова: ВВП за паритетом купівельної спроможності, макроекоміка, часові ряді, динамічні економічні системи, динамічний факторний аналіз.

Постановка проблеми. Номінальний та реальний ВВП, а також ВВП, розрахований за паритетом купівельної спроможності (ВВП за ПКС) $є$ одними із найважливіших показників розвитку економіки окремих регіонів і країн, а також їх об'єднань. Вони характеризують кінцевий результат виробничої діяльності у сфері матеріального і нематеріального виробництва. Оскільки ВВП або ВВП за ПКС є головними індикаторами економічного розвитку i найповнішими показниками сумарного обсягу виробництва товарів та послуг за певний період часу, то їх зміни доцільно використовувати для оцінки динаміки макроекономіки в цілому, нехтуючи в першому наближенні іншими макроекономічними показниками. Зауважимо, що номінальний ВВП як сума всіх товарів $\mathrm{i}$ послуг, вироблених в країні за певний період, може бути розрахованим в національній валюті, а ВВП за ПКС, який звичайно використовують для порівняння між собою розвитку різних країн, переводять у світову валюту - долари США.

У статті запропоновано підхід до проведення порівняльного аналізу та моделювання зміни за часом ВВП за ПКС в економіці деяких країн Свропи на протязі останніх 20 років та досліджуються закономірності їх спільного розвитку. Для дослідження обрана група

(C) Катуніна О.С., кандидат економічних наук, доцент, доцент кафедри економікоматематичного моделювання ДВНЗ "Київський національний економічний університет імені Вадима Гетьмана", м. Київ, тел:0663464894, еmail: prommet@ukr.net, ORCID ID: https://orcid.org/0000-0001-7584-0037 пострадянських країн - Латвія, Литва, Естонія, Білорусь, Україна, постсоціалістична Угорщина і капіталістична Фінляндія. Слід зауважити, що країни Прибалтики, Угорщина i Фінляндія $\epsilon$ представниками $\mathrm{EC}$, але крім Фінляндії, вони були прийняті до $Є С$ тільки після розпаду Радянського Союзу. Тоді ж на самостійний шлях розвитку стали Білорусь і Україна. Крім того на вибір саме цих країн вплинуло те, що Фінляндія, як і країни Прибалтики, входить до ради держав Балтійського моря, а Угорщина i Білорусь $є$ безпосередніми сусідами України.

Макроекономіку окремої країни будемо розглядати як складну динамічну економічну систему (ДЕС) із багатьма внутрішніми та причинно-наслідковими зв'язками, які потребують поглиблених досліджень. У статті для побудови відповідних моделей таких систем використовувались статистичні значення макропоказників, наведених на сайті світової економіки ereport.ru [1] (до 2016 року) i електронного довідника CIA World Factbook [2] (2016, 2017 pp.), а для оцінки прогнозу - списки МВФ та Всесвітнього банку [3] (2017р.).

Під ДЕС будемо розуміти об'єкт або процес, для яких визначено поняття станів як сукупності значень деяких показників в певний момент часу і відомі їх зміни $з$ плином часу, тобто задана еволюція системи. Для визначення тренду ДЕС на грунті емпіричних часових рядів, які утворюють значення показників, використовують статичний i динамічний факторний (ДФА) аналізи, для успішного застосування яких потрібно визначити показники, які визначають тенденцію розвитку системи. Оцінку впливу кожного із показників на 
тренд іiі розвитку можливо оцінити, визначаючи кореляційний матриці і матриці коваріації ЧР.

Практичне застосування динамічних моделей суттєво обмежується властивостями складності, емерджентності, інерційності і певної невизначеності економічних систем як об'єктів моделювання. $\mathrm{y}$ розпорядженні дослідників економічних процесів фактично є тільки дані

$$
y_{j}(t)=\left\{y_{j}\left(t_{1}\right), y_{j}\left(t_{2}\right), y_{j}\left(t_{2}\right), \ldots, y_{j}\left(t_{n}\right)\right\},(j=1,2, \ldots, k ; i=1,2, \ldots, n .),
$$

де моменти часу $t_{i}$ належать проміжку $t_{i} \in[0, T]$ на якому розглядається розвиток системи.

Для дослідження окремих ЧР використовують лінійний і нелінійний авторегресійний аналізи $R(p)$ та $A R(p)$ процеси порядку $p$ [4]. Означені методи виявляються особливо успішними для дослідження довгих ЧР $\mathrm{i}$ визначення періодичних складових. Інший, на цей час менш поширений шлях, полягає в застосуванні теорії дискретних відображень [5], які можна застосовувати і для коротких ЧР. При статистики, тобто, зафіксовані у певні моменти часу $t_{i}$ значення обраних $k$ показників $y_{j}(t)$, якими можливо деяким чином охарактеризувати систему. Показники утворюють часові ряди (ЧР), тобто формально обмежені числові послідовності: цьому обидва підходи спираються на припущення, що вся інформація про спостережуваний період і подальший розвиток ДЕС міститься у самому ЧР.

При використанні теорії відображень значення ЧР в момент часу $t+1$, яке позначимо $N_{t+1}$, визначають через значення $N_{t}$ у попередній момент часу $t$ (тобто показник повністю визначається обраним моментом часу). Це приводить до розгляду різницевих рівнянь, або дискретних динамічних систем

$$
N_{t+1}=f\left(N_{t}\right) \text { або } f(N) \rightarrow N, N \in \mathbf{Z}, t \in \mathrm{R},
$$

де $f$ - відоме відображення, яке, може, додатково залежати від деяких параметрів, $\mathbf{Z}, \mathbf{R}$ - множини цілих і дійсних чисел відповідно.

Дослідження рівнянь типу (2) проводять, виходячи 3 якісного аналізу відображень, який спирається на знаходженні нерухомих точок, визначенні іх типу і стійкості. Нерухомі точки $N *$ - це розв'язки рівняння $f(N)=N$, а точка $N *$ буде стійкою, якщо функція $f$ є оборотною, і виконується нерівність $\left|f_{N}^{\prime}\left(N^{*}\right)\right|<1$. Якщо рівняння (2) залежить від параметрів, то при їх

$$
F_{m}(t)=\sum_{j=1}^{k} a_{j m} y_{j}^{(m-1)}(t), \quad m=1,2, \ldots, M, t \in[0, T]
$$

у вигляді лінійної комбінації заданих або резідуальних ЧР $[10,11]$. До другої групи входять

динамічні рівняння факторів, кожне 3 яких $є$ $A R(L)$ оцінкою $m$-го фактора

$$
\hat{F}_{m}(t)=c_{m 0}+\sum_{l=1}^{L} c_{l m} F_{m}(t-l), m=1,2, \ldots, M, t \in[0, T],
$$

де $L$ - тривалість запізнення (лага), $c_{m 0}, c_{l m}-$ коефіцієнти авторегресії.

Це означає, що на відміну від схем векторної авторегресії рівняння авторегресій будуються

$$
\hat{y}_{j}(t)=\sum_{m=1}^{M} d_{j m}^{(0)}+\sum_{m=1}^{M} d_{j m} F_{m}(t), j=1,2, \ldots, k, t \in[0, T]
$$


які виражають ЧР через динамічні фактори і визначають їх апроксимацію.

Для отримання прогнозних значень приймається допущення про часову інваріантність
ДЕС. Це означає, що рівняння (3)-(5) застосовні і в «майбутньому». Тоді, після знаходження прогнозних значень факторів $\hat{\hat{F}}_{m}(t)$ за допомогою рівнянь (4) при $t>T$

$$
\hat{\hat{F}}_{m}(t)=c_{m 0}+\sum_{l=1}^{L} c_{l m} F_{m}(t-l), t>T
$$

будується прогноз $\hat{\hat{y}}_{j}(t)$ для кожного ряду,

використовувати їх прогнозні значення для чого в рівняннях (5) замість факторів слід

$$
\hat{\hat{y}}_{j}(t)=\sum_{m=1}^{M} d_{j m}^{(0)}+\sum_{m=1}^{M} d_{j m} \hat{\hat{F}}_{m}(t), t>T, j=1,2, \ldots, k,
$$

У загальному випадку задача полягає у визначенні коефіцієнтів $a_{j m}, c_{l m}, d_{j m} \mathrm{y}$ рівняннях (3)-(5). У розробленому алгоритмі [10] це здійснюється при побудові розв'язків $M$ задач нелінійного програмування для послідовного визначення динамічних факторів. Реалізація в цьому алгоритмі можливості мінімізації похибки для окремого ЧР в ex-post прогнозі приводить до мультиваріантного прогнозу, застосованого в [11] для аналізу динаміки світових біржевих індексів. Такий підхід відображає ймовірнісний характер процесу прогнозування i, оскільки визначає інтервали можливих значень прогнозів, частково розв'язує загальну задачу визначення шляхів еволюції ДЕС за даними спостережень.

Мета роботи полягає в побудові динамічних факторних моделей для опису динаміки ВВП за ПКС деяких європейських і пострадянських країн, встановлення шляхом порівняльного аналізу загальних тенденцій їх зміни і визначення прогнозних значень цих показників на найближчі роки з використанням ДФА.

Аналіз останніх досліджень і публікацій. Динамічне факторне моделювання за методом ДФА, як відмічалось вище, $\epsilon$ поєднанням факторного аналізу і авторегресійного аналізу ЧР, включаючи обчислені 3 багатовимірних ЧР матриці автокореляції. Такі моделі використовуються для макроекономічного аналізу систем показників, ділових циклів та прогнозування. Підхід ДФА було розроблено для обробки великих панельних ЧР, де кожен ЧР $є$ сумою загальної і ідіосинкразійної компонент. Загальна складова ЧР визначається декількома основними некорельованими i неспостережуваними загальними факторами, які можна отримати застосуванням лінійного фільтру до набору даних (можливо із запізненням). При цьому узагальнена ДФМ використовує динамічну коваріаційну структуру даних і співвідношення між різними змінними в різних точках одночасно. Це суттєво відрізняє такий підхід від моделі прогнозу, яка запропонована Дж. Стоком і М. Уотсоном (J. Stock and M. Watson) в $[12,13]$ i грунтується на проектуванні на стягнутий простір статичних головних компонент даних [14].

Означене представлення варіанта ДФА вперше використали Форні і Рейхлін (Forni and Reichlin) у 1998 р. [15], а пізніше було розвинуто в роботах [16-21]. Автори запропонували узагальнену ДФМ, яка дозволила обмежити взаємну кореляцію серед окремих компонент і запропонували цей метод для використання потенційно корисної інформації у великих панельних даних.

Інші підходи до побудови ДФМ запропоновано Капетаніосом і Марцелліно (Kapetanios, Marcellino) [22], Kapetanios [23], a його застосування - у роботах [24-26]. У дослідженні [27] наведено посилання на значну кількість досліджень статистичних даних економік США і Європи, які доводять суттєве покращення прогнозів макроекономічних змінних при використанні методу ДФА.

3 викладеного випливає, що застосування ДФА надає досліднику великі можливості при розгляді еволюції ДЕС різного складу. Разом 3 тим, ефективність розроблених моделей буде суттєво залежати від конкретного складу системи (кількості і вибору показників), обраного методу побудови динамічних факторів, їх кількості, тривалості лагу i, можливо, інших параметрів моделей. Ці питання на цей час вирішені недостатньо, потребують додаткових досліджень і можуть бути ефективно вирішеними тільки при розгляді конкретних динамічних систем.

Формулювання цілей статті. Метою роботи $\epsilon$ побудова ДФМ для опису динаміки ВВП за ПКС деяких європейських та пострадянських країн, встановлення шляхом порівняльного аналізу загальних тенденцій їх зміни $\mathrm{i}$ визначення 
прогнозних значень цих показників на найближчі роки $з$ використанням методу керованого ДФА.

Опис основного матеріалу дослідження. Основні отримані результати зводяться до наступних. При знаходжені прогнозних значень існує два шляхи пошуку. В першому варіанті прогноз робиться одночасно на декілька кроків вперед (інтервальний прогноз). В другому варіанті, який можна назвати рекурсивним, прогноз виконується тільки на один крок вперед, тобто спочатку знаходиться значення $\hat{\hat{y}}_{j}\left(t_{n+1}\right)$. Ці значення дописуються в кінець заданих ЧР, модель будується знов, i подальший прогноз здійснються вже при обробці нових, розширених ЧР вигляду

$$
y_{j}^{*}(t)=\left\{y_{j}\left(t_{1}\right), y_{j}\left(t_{2}\right), \ldots, y_{j}\left(t_{i}\right), \ldots, y_{j}\left(t_{n}\right), \hat{\hat{y}}_{j}\left(t_{n+1}\right)\right\} .
$$

Процес продовжується до вичерпання проміжку

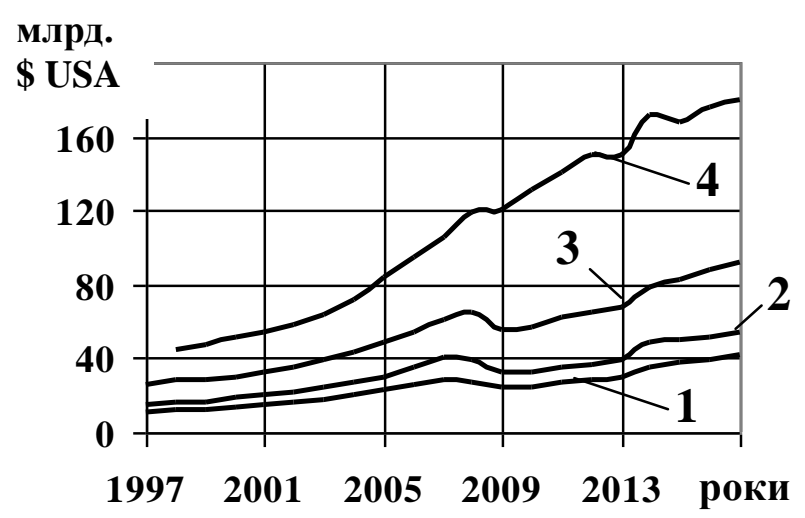

Рис. 1. Динаміка ВВП за ПКС різних країн: 1 - Естонія, 2 - Латвія, 3 - Литва,

\section{4 - Беларусь.*}

*Джерело: авторська розробка за даними [1].

3 наведених графіків випливає, що незважаючи на різний обсяг ВВП за ПКС і різний суспільно-економічний устрій країн, динаміка його зміни має дуже схожий вигляд. При суттєвому, майже монотонному, зростанні цього макроекономічного показника до 2007 року, у пізнішому періоді зростання суттєво уповільнюється, і спостерігаються значні коливання, найбільш помітні для Білорусі, України і Фінляндії. При цьому після 2013 року маємо вже падіння обсягу ВВП за ПКС для України, Білорусі i частково для Угорщини. Локальні максимуми, які припадають на 2008 рік і 2013 рік, спостерігаються для усіх країн, що особливо добре помітно на рис. 1 для Білорусі і країн Балтії. Падіння ВВП за ППС прогнозування, і в розробленій новій версії ДФА при застосуванні схеми мультиваріантного прогнозу на кожному кроці в якості $\hat{\hat{y}}_{j}\left(t_{n+1}\right)$ використовуються середні арифметичні отриманих значень прогнозу кожного ЧР. Зауважимо, що для отримання достатньо надійного прогнозу довжина проміжку прогнозування не повинна перевищувати 1/3 довжини заданих ЧР.

Наведемо деякі результати виконаних досліджень.

Для визначення загальних тенденцій спочатку розглянемо зміну ВВП за ПКС різних країн з 1997 по 2016 роки, користуючись даними сайту[1]. Динаміка цього показника показана на рис. 1, 2, i внаслідок значної різниці в обсязі ВВП за ПКС для наочності країни розділені на групи за його величиною

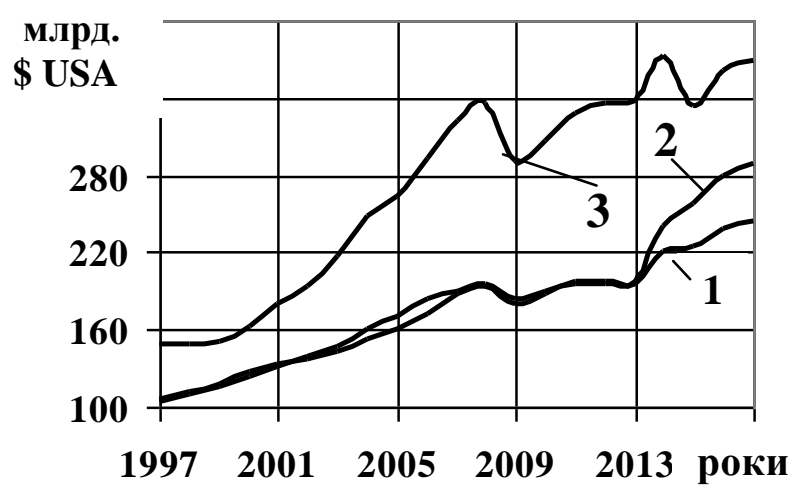

Рис. 2. Динаміка ВВП за ПКС різних країн: 1 - Фінляндія, 2 - Угорщина, 3 - Україна.*

спостерігається у 2014, 2015 рр. для Беларусі, України i частково Литви, у той час, як для Фінляндії і Угорщини, навпаки, навіть має місце не тільки саме зростання, а і збільшення його темпів. Зауважимо, що різка зміна показника для України, очевидно, пов'язана 3 подіями 20142015 рр. в Києві, які також вплинули на економіку сусідніх країн.

Для отримання інтервальних прогнозів ВВП за ППС спочатку були розглянуті ДЕС, складені 3 чотирьох макроекономічних показника окремих країн. Цими показниками були номінальний ВВП, ВВП за ПКС, експорт i імпорт. Для вказаних систем на базовому періоді 1988 - 2016 роки 3 використанням даних, наведених в [1], які на час написання статті містять результати тільки до 
2016 року, були побудовані відповідні моделі ДФА і проведені необхідні розрахунки. Отримані результати інтервального прогнозу для деяких країн на 2017 - 2019 роки і контрольні значення ВВП за ПКС за 2017 рік, наведені в списках МВФ

і Світового банку [3], представлені в табл. 1.

Прогнозні значення ВВП за ПКС на 2017-2019 роки*

\begin{tabular}{|c|c|c|c|c|c|c|}
\hline \multirow[t]{2}{*}{ Країна } & \multicolumn{3}{|c|}{$\begin{array}{c}\text { Прогнозні значення ВВП за ПКС (млрд. \$ США), } \\
\text { визначені на періоді 1998-2016 роки при } \\
\text { інтервальному прогнозі на } \\
\end{array}$} & \multicolumn{2}{|c|}{$\begin{array}{c}\text { Контрольні значення } \\
\text { показників за } 2017 \text { рік, млрд. } \\
\text { \$ США }\end{array}$} & \multirow{2}{*}{$\begin{array}{c}\text { Середня } \\
\text { похибка } \\
\text { прогнозу на } \\
2017 \text { рік }\end{array}$} \\
\hline & 2017 рік & 2018 рік & 2019 рік & $\begin{array}{c}\text { за даними } \\
\text { МВФ }\end{array}$ & $\begin{array}{c}\text { за даними } \\
\text { СБ }\end{array}$ & \\
\hline Латвія & 57,5 & 59,8 & 61,7 & 53,9 & 53,6 & $7,2 \%$ \\
\hline Естонія & 39,3 & 39,5 & 39,3 & 41,6 & 41,8 & $-5,8 \%$ \\
\hline Угорщина & 271,24 & 275,5 & 276,7 & 280 & 275 & $-2,2 \%$ \\
\hline Фінляндія & 230,6 & 232,6 & 232,4 & 244 & 247 & $-5,7 \%$ \\
\hline
\end{tabular}

*Джерело: власні розрахунки.

3 наведених даних випливає, що прогнозується зростання ВВП за ПКС для всіх країн, хоча темпи цього зростання відрізняються. Оскільки дані МВФ i СБ не співпадають, то для оцінки фактичної похибки прогнозу на 2017 рік використовувались їх середні значення, i отримані значення наведені в останньому стовпчику табл. 1. Виявилось, що розроблені моделі для Латвії показують порівняно 3 фактичним завищене, а для інших країн занижене зростання. При цьому відносні похибки прогнозів із врахуванням знаку знаходяться в межах від $-5,7 \%$ до 7,2 \%. Зауважимо, що інтервальні прогнози було отримано 3 використанням даних з сайту [1], а для контролю внаслідок відсутності відповідних значень за 2017 рік використані з [3]. Крім того при розрахунках не враховувалась мультиваріантність прогнозу і моделі ДФА налаштувались на конкретний ЧР (ВВП за ПКС), чим, як показали подальші числові експерименти, i пояснюється досить велика похибка прогнозу.

Наведені результати свідчать про наявність певних загальних тенденцій у динаміці економіки розглянутих країн, а топологічна схожість графіків на рис. 1, 2 дозволяє припустити, що динаміка ВВП за ППС обумовлена певними однаковими зовнішніми чинниками.

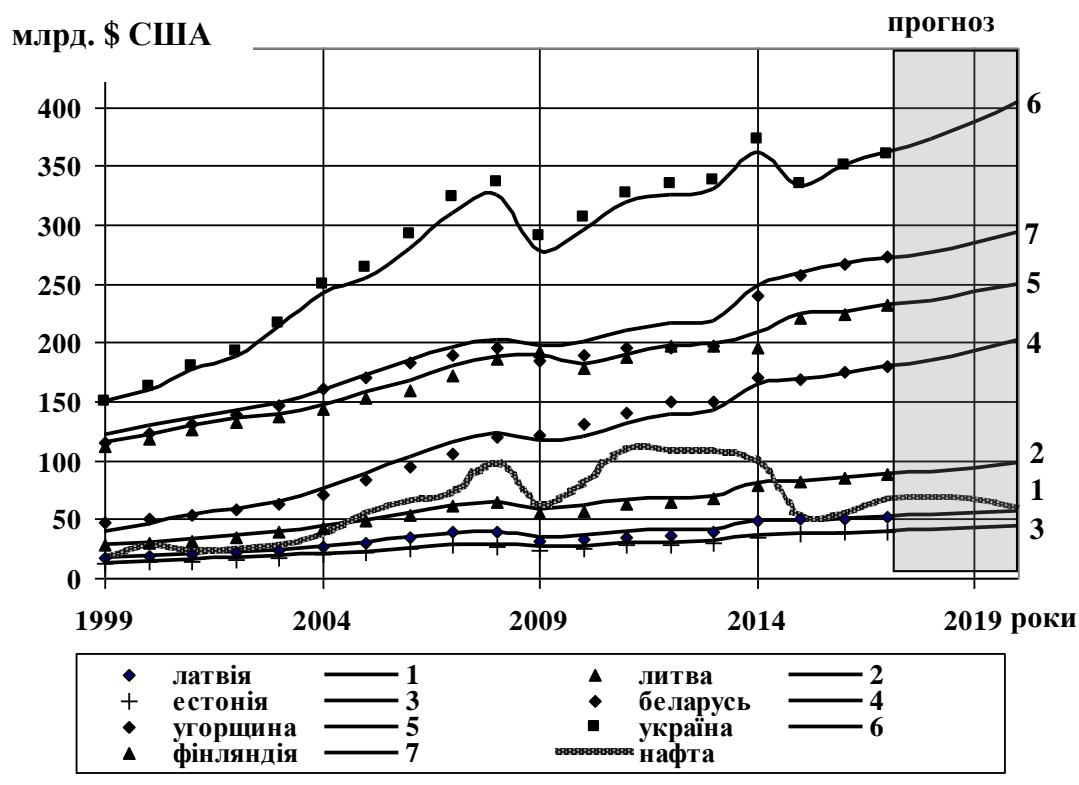

Рис. 3. Динаміка ВВП за ПКС різних країн та її опис трифакторною моделлю ДФА 3 рекурсивним прогнозом і зміна світових цін на нафту Brent.*

*Джерело: авторська розробка за власними розрахунками.

Це спонукало об'єднати показники і розглянути ДЕС, складену з ВВП за ППС різних країн із використанням статистичних даних за 1999-2017 роки для отримання прогнозу на три наступних роки. Були побудовані моделі для різної кількості факторів при значені лага $L=3$ 3 використанням рекурсивного прогнозу i 
врахуванням його мультиваріантності. Розрахунки показали, що найкраща точність опису динаміки системи досягається для трифакторних моделей. Деякі результати розрахунків для цього випадку приведено на рис. 3 і в табл. 2. Вище відзначалось, що певна аналогія в динаміці ВВП за ПКС різних країн може бути причинена зовнішніми чинниками. Тому для оцінки такого впливу на рис. 3 показана зміна світових цін на нафту марки Brent за даними статистики до 2018 р. включно, але цей показник не входив до системи ЧР.

Таблиця 2.

Прогнозні значення ВВП за ПКС на 2018-2020 роки*

\begin{tabular}{|c|c|c|c|}
\hline \multirow{2}{*}{ Країна } & \multicolumn{3}{|}{$\begin{array}{r}\text { Прогнозні значення ВВП за ПКС (млрд. \$ США), визначені на базовому } \\
\text { періоді 1998-2017 роки при рекурсивному прогнозі на }\end{array}$} \\
\cline { 2 - 4 } & 2018 рік & 2019 рік & 2020 рік \\
\hline Латвія & 53,99 & 55,12 & 57,54 \\
\hline Литва & 90,24 & 93,74 & 97,67 \\
\hline Естонія & 40,59 & 42,15 & 43,90 \\
\hline Беларусь & 184,9 & 193,1 & 202,3 \\
\hline Угорщина & 276,4 & 284,2 & 404,2 \\
\hline Україна & 372,9 & 387,6 & 249,5 \\
\hline Фінляндія & 235,6 & 242,4 & \\
\hline
\end{tabular}

*Джерело: власні розрахунки.

3 наведених даних випливає, що для розглянутих країн 3 певними коливаннями спостерігається зростання обраного показника. Звертають на себе увагу 2008 - 2009 роки, коли різке падіння світових цін на нафту співпало із суттєвим падінням ВВП за ППС, але одночасно, падіння цін у 2014 році не зупинило його зростання. Це свідчить не тільки про зв'язок із світовими цінами, на нафту, але і про існування інших зовнішніх чинників. Рекурсивний прогноз, чисельні значення якого для різних країн наведено в табл. 2, також указує на зростання ВВП за ППС у прогнозному періоді. На жаль, отримані результати можна буде перевірити тільки після появи в довідкових джерелах відповідних статистичних даних, але i зараз можна стверджувати, що за відсутності несподіваних різких збурень у світовій економіці відносна похибка не буде перевищувати 10 \%, про що свідчить співпадіння розрахованих i фактичних рівнів ЧР в базовому періоді на рис. 3 .

Висновки i перспективи подальших досліджень. Викладені результати практичного дослідження із моделювання динаміки ВВП за ПКС обраних країн i визначення прогнозних значень цих показників, свідчать про ефективність та високу прогностичну якість розробленої моделі ДФА. На відміну від існуючих інструментів аналізу ДЕС, при динамічному факторному моделюванні 3 використанням цієї версії ДФА у дослідника виникає можливість активного втручання в процес побудови відповідних моделей для мінімізації похибки довільно обраного, тобто цільового для систем управління показника в процесі проведення ex-post аналізу. Можливість мінімізації похибки саме цільового показника забезпечує можливість одержання мультіваріантного прогнозу, який визначає $k$ можливих шляхів подальшої еволюції динамічних систем, що складаються $3 k$ показників. Ефективність такого прогнозу проілюстровано у статті [11]. У розробленій схемі рекурсивного прогнозування на черговому кроці побудови моделі використовуються усереднені значення iз $k$ отриманих прогнозів, що дає можливість врахувати вплив кожного ЧР і певним чином покращити надійність прогнозування.

Наведені результати побудови альтернативних прогнозів за різними сценаріями налаштування моделі ДФА підтверджують ефективність запропонованого підходу. Зокрема, у здійсненому модельному дослідженні похибка прогнозу ВВП за ППС для окремих країн не перевищувала 7 \% навіть без врахування складних причиннонаслідкових взаємозалежностей в системі показників. Можливість отримання такого рівня достовірності відкриває нові можливості для аналізу динаміки довільних економічних систем і дозволяе запропонувати використання розробленого підходу в науково-дослідницькій практиці. Верифікація одержаних у проведеному дослідженні прогнозних значень зростання ВВП за ППС окремих країн здійснюватиметься 3 появою оновлених статистичних даних. 


\section{СПИСОК ВИКОРИСТАНИХ ДЖЕРЕЛ}

1. Экономические показатели: статистика, графики: URL: www.ereport.ru/ (дата звернення: 31.03.2019).

2. Central Intelegens Agency / The World Factbook: URL: https://www.cia.gov/library/publications/the-worldfactbookl

3. URL: https://uk.wikipedia.org/ Список_країн_за_ВВП_(ПКС).

4. Cowpertwait P.S.P., Metcalfe A.V. Introductory Time Series with R. Springer, 2009. 262 p.

5. Романовский И. В. Дискретный анализ. - 4-е изд. Санкт-Петербург: Невский Диалект; БХВ-Петербург, 2008. $336 \mathrm{c}$.

6. Sezgin F., Kinay B. A dynamic factor model of the evaluation of the phinancial crisis in Turkey. Bull. Soc. Sci. Med. Grand Duche Luxemb. 2010. Spec. No 1. P. 109-117.

7. AJournallevskis V., Dāvidsons G. Dynamic factor models in forecasting latvia's Gross domestic product. Department of the Bank of Latvia, 2, 2008. 24 p.

8. Bai J., Ng S. Large Dimensional Factor Analysis. Foundations and Trends in Econometrics. 2008. Vol. 3(2). P. 89-163.

9. Pe ñ a D., Poncela P. Nonstationary dynamic factor analysis. JOURNALL. of Statistical Planning and Inference. 2006. No. 136. P. 1237-1257.

10. Катуніна О.С. Прогнозування процесів насичення ринку на базі динамічних факторних моделей. Моделювання та інформаційні системи в економіціі. 2014. Вип.90. С. 106-125.

11. Катунина О.С. Прогнозное факторное моделирование индексов фондового рынка. Бізнес Інформ. 2017. № 11. C. 197-202.

12. Stock J., Watson M. Macroeconomic Forecasting Using Diffusion Indexes. Journal of Business and Economic Statistics. 2002. Vol.20. P: 147-162.

13. Stock J., Watson M. Forecasting Using Principal Components From a Large Number of Predictors. Journall of the American Statistical Association. 2002. Vol. 97. P: 1167-1179.

14. Schneider M., Spitzer M. Forecasting Austrian GDP Using The Generalized Dynamic Factor Model. OENB Working Paper. 2004. No: 89.

15. Forni M., Reichlin L. Lets' Get Real: A Factor Analytical Approach to Disaggregated Business Cycle Dynamics. Review of Economic Studies. 1998. № 65: P. 453-473.

16. Forni M., Lippi M. The Generalized Dynamic Factor Model: Representation Theory. Econometric Theory, 2001. Vol. 17. P: 1113-1141.

17. Forni M., Hallin M., Lippi M., Reichlin L. The generalized Dynamic Factor Model: Identification and Estimation. The Review of Economics and Statistics, 2000. Vol. 82. P. 540-554.

18. Forni M., Hallin M., Lippi M., Reichlin L. Coincident and Leading Indicators For The Euro Area. Economic JOURNALournal. 2001. Vol, 111: P. 62-85.

19. Forni M., Hallin M., Lippi M., Reichlin L. Do Financial Variables Help Forecasting Inflation and Real Activity in the Euro Area? Journal of Monetary Economics. 2003. Vol. 50: P. 1243-1255.

20. Forni M., Hallin M., Lippi M., Reichlin L. The Generalized Dynamic Factor Model: Consistency and Rates. 2004. Journal of Econometrics. Vol. 119: P. 231-255.

21. Forni M., Hallin M., Lippi M., Reichlin L. The Generalized Dynamic Factor Model: One-Sided Estimation and Forecasting. 2005. Journal of the American Statistical Association. Vol.100. P. 830-840.

22. Kapetanios G., Marcellino M. A Parametric Estimation Method For Dynamic Factor Models of Large Dimensions. 2004. Queen Mary University of London. Working Paper. No: 489.

23. Kapetanios G. A Note on Modelling Core Inflation for the UK Using a New Dynamic Factor Estimation Method and a Large Disaggregated Price Index Data Set. Economics Letters. 2004. Vol. 85. P. 63-69.

24. Camba-Mйndez G., Kapetanios G. Forecasting Euro Area Inflation Using Dynamic Factor easures of Underlying Inflation. Journal of Forecasting. 2005. Vol. 25: P/ 491-503.

25. Schumacher C. Forecasting German GDP Using Alternative Factor Models Based on Large Data Sets. Journal of Forecasting. 2007. Vol. 26: P. 271-302.

26. Eickmeier S., Ziegler C. How Successful are Dynamic Factor Models at Forecasting Output and Inflation? A Meta-Analytic Approach. Journal of Forecasting, 27: 237-265. 116. Layout Bulletin 02.06.2010 10:31 Uhr Seite.

27. Giannone D., Matheson D. A New Core Inflation Indicator for New Zealand. International JOURNAL. of Central Banking. 2007. Vol. 3: P. 145-180.

\section{REFERENCES}

1. Ekonomycheskye pokazately: statystyka, hrafyky [Economical indicators, statistics, graphics]. Retrieved from: www.ereport.ru [in Russian].

2. Central Intelegens Agency. The World Factbook: Retrieved from: https://www.cia.gov/library/publications/theworld-factbook/ [in English].

3. Retrieved from: https://uk.wikipedia.org/ List of countries by GDP (PPP) [in English].

4. Cowpertwait, P.S.P., Metcalfe, A.V. (2009). Introductory Time Series with R. Springer [in English].

5. Romanovskiy, I.V. (2008). Diskretnyy analiz [Discrete analysis]. St. Petersburg: Nevsky Dialect; BHVPetersburg [in Russian]. 
6. Sezgin, F., Kinay, B. (2010). A dynamic factor model of the evaluation of the phinancial crisis in Turkey - Bull.

Soc. Sci. Med. Grand Duche Luxemb. Spec., 1, 109-117 [in English].

7. Ajevskis, V., Dāvidsons, G. (2008). Dynamic factor models in forecasting latvia's Gross domestic product Department of the Bank of Latvia, 2, 24. [in English].

8. Bai, J., Ng, S. (2008). Large Dimensional Factor Analysis. Foundations and Trends in Econometrics. - 3(2), 89163. [in English].

9. Pe ñ a, D., Poncela, P. (2006). Nonstationary dynamic factor analysis - Journal of Statistical Planning and Inference, 136, 1237-1257. [in English].

10. Katunina, O.S. (2014). Prohnozuvannia protsesiv nasychennia rynku na bazi dynamichnykh faktornykh modelei [Forecasting processes of saturation of the market based on dynamic factor models]. Modelyuvannya ta informatsiyni systemy v ekonomitsi - Modeling and Information Systems in Economics, 90, 106-125. [in Ukrainian].

11. Katunina, O.S. (2017). Prognoznoye faktornoye modelirovaniye indeksov fondovogo rynka [Predictive factor modeling of stock market indices] - Business Inform, 11, 197-202. [in Russian].

12. Stock, J., Watson, M. (2002). Macroeconomic Forecasting Using Diffusion Indexes - Journal of Business and Economic Statistics, 20, 147-162. [in English].

13. Stock, J., Watson, M. (2002). Forecasting Using Principal Components From a Large Number of Predictors Journal of the American Statistical Association, 97, 1167-1179. [in English].

14. Schneider, M., Spitzer, M. (2004). Forecasting Austrian GDP Using The Generalized Dynamic Factor Model OENB Working Paper, 89. [in English].

15. Forni, M., Reichlin, L. (1998). Lets' Get Real: A Factor Analytical Approach to Disaggregated Business Cycle Dynamics - Review of Economic Studies, 65,. 453-473. [in English].

16. Forni, M., Lippi, M. (2001). The Generalized Dynamic Factor Model: Representation Theory - Econometric Theory, 17, 1113-1141. [in English].

17. Forni, M., Hallin, M., Lippi, M., Reichlin, L. (2000). The generalized Dynamic Factor Model: Identification and Estimation - The Review of Economics and Statistics, 82, 540-554. [in English].

18. Forni M., Hallin M., Lippi M., Reichlin L. (2001). Coincident and Leading Indicators For The Euro Area Economic Journal, 111, 62-85. [in English].

19. Forni, M., Hallin, M., Lippi, M., Reichlin, L. (2003). Do Financial Variables Help Forecasting Inflation and Real Activity in the Euro Area? - Journal of Monetary Economics, 50, 1243-1255. [in English].

20. Forni, M., Hallin, M., Lippi, M., Reichlin, L. (2004.). The Generalized Dynamic Factor Model: Consistency and

Rates - Journal of Econometrics, 119, 231-255. [in English].

21. Forni, M., Hallin, M., Lippi, M., Reichlin, L. (2005). The Generalized Dynamic Factor Model: One-Sided

Estimation and Forecasting - Journal of the American Statistical Association, 100, 830-840. [in English].

22. Kapetanios, G., Marcellino, M. (2004). A Parametric Estimation Method For Dynamic Factor Models of Large Dimensions - Queen Mary University of London. Working Paper, 489. [in English].

23. Kapetanios, G. (2004.). A Note on Modelling Core Inflation for the UK Using a New Dynamic Factor Estimation Method and a Large Disaggregated Price Index Data Set - Economics Letters, 85, 63-69. [in English].

24. Camba-Mйndez, G., Kapetanios, G. (2005). Forecasting Euro Area Inflation Using Dynamic Factor easures of Underlying Inflation - Journal. of Forecasting, 25, 491-503. [in English].

25. Schumacher, C. (2007). Forecasting German GDP Using Alternative Factor Models Based on Large Data Sets - Journal of Forecasting, 26, 271-302. [in English].

26. Eickmeier, S., Ziegler, C. (2010). How Successful are Dynamic Factor Models at Forecasting Output and Inflation? A Meta-Analytic Approach. - Journal. of Forecasting, 27, 237-265. [in English].

27. Giannone, D., Matheson, D. (2007). A New Core Inflation Indicator for New Zealand. International - Journal. of Central Banking, 3, 145-180. [in English].o 